\title{
Circulating pre-treatment Epstein-Barr virus DNA as prognostic factor in locally-advanced nasopharyngeal cancer in a non- endemic area
}

\author{
Salvatore Alfieri ${ }^{1}$, Nicola Alessandro Iacovelli ${ }^{2}$, Sara Marceglia ${ }^{3}$, Irene Lasorsa $^{3}$, \\ Carlo Resteghini' ${ }^{1}$, Francesca Taverna ${ }^{4}$, Arabella Mazzocchi ${ }^{4}$, Ester Orlandi' ${ }^{2}$ Marco \\ Guzzo $^{5}$, Roberto Bianchi ${ }^{5}$, Diana Fanti ${ }^{6}$, Laura Pala7, Sara Racca ${ }^{7}$ Roee Dvir ${ }^{8}$, \\ Pasquale Quattrone ${ }^{9}$, Annunziata Gloghini ${ }^{9}$, Chiara Costanza Volpi ${ }^{9}$, Roberta \\ Granata $^{1}$, Cristiana Bergamini ${ }^{1}$, Laura Locati ${ }^{1}$, Lisa Licitra ${ }^{1,10}$ and Paolo Bossi ${ }^{1}$ \\ ${ }^{1}$ Department of Medical Oncology 3, Fondazione IRCCS Istituto Nazionale dei Tumori, Milan, Italy \\ ${ }^{2}$ Department of Radiation Oncology, Fondazione IRCCS Istituto Nazionale dei Tumori, Milan, Italy \\ ${ }^{3}$ Department of Engineering and Architecture, University of Trieste, Trieste, Italy \\ ${ }^{4}$ Laboratory of Immunohematology \& Transfusion Medicine, Fondazione IRCCS Istituto Nazionale dei Tumori, Milan, Italy \\ ${ }^{5}$ Department of Head and Neck Surgery, Fondazione IRCCS Istituto Nazionale dei Tumori, Milan, Italy \\ ${ }^{6}$ Laboratory of Clinical Chemistry and Microbiology, ASST Grande Ospedale Metropolitano Niguarda, Milan, Italy \\ ${ }^{7}$ Department of Medical Oncology of Melanoma and Sarcoma, Istituto Europeo di Oncologia, Milan, Italy \\ ${ }^{8}$ Laboratory of Clinical Microbiology \& Virology, San Raffaele IRCCS Hospital, Milan, Italy \\ ${ }^{9}$ Department of Pathology, Fondazione IRCCS Istituto Nazionale dei Tumori, Milan, Italy \\ ${ }^{10}$ Department of Medical Oncology 3, University of Milan, Milan, Italy \\ Correspondence to: Salvatore Alfieri, email: salvatore.alfieri@istitutotumori.mi.it \\ Keywords: nasopharyngeal cancer, Epstein-Barr virus, prognosis, head and neck cancer, non endemic \\ Received: February 06, $2017 \quad$ Accepted: April 12, $2017 \quad$ Published: May 11, 2017 \\ Copyright: Alfieri et al. This is an open-access article distributed under the terms of the Creative Commons Attribution License 3.0 \\ (CC BY 3.0), which permits unrestricted use, distribution, and reproduction in any medium, provided the original author and source \\ are credited.
}

\section{ABSTRACT}

The prognostic value of pre-treatment Epstein-Barr Virus (EBV) DNA viral load for non-endemic, locally-advanced, EBV-related nasopharyngeal cancer (NPC) patients is yet to be defined. All patients with EBV encoded RNA (EBER)-positive NPC treated at our Institution from 2005 to 2014 with chemotherapy (CT) concurrent with radiation (RT) +/- induction chemotherapy (ICT) were retrospectively reviewed. Pre-treatment baseline plasma EBV DNA (b-EBV DNA) viral load was detected and quantified by PCR. Median b-EBV DNA value was correlated to potential influencing factors by univariate analysis. Significant variables were then extrapolated and included in a multivariate linear regression model. The same variables, including b-EBV DNA, were correlated with Disease Free Survival (DFS) and Overall Survival (OS) by univariate and multivariate analysis.

A total of 130 locally-advanced EBER positive NPC patients were evaluated. Overall, b-EBV DNA was detected in 103 patients (79.2\%). Median viral load was 554 copies/mL (range 50-151075), and was positively correlated with $T$ stage $(p=0.002), N 3 a-b$ vs N0-1-2 stage $(p=0.048)$, type of treatment (ICT followed by CTRT, $p=0.006)$ and locoregional and/or distant disease recurrence $(p=0.034)$. In the overall population, DFS and OS were significantly longer in patients with pre-treatment negative EBV DNA than in positive subjects at the multivariate analysis.

Negative b-EBV DNA can be considered as prognostic biomarker of longer DFS and OS in NPC in non-endemic areas. This finding needs confirmation in larger prospective series, with standardized and inter-laboratory harmonized method of plasma EBV DNA quantification. 


\section{INTRODUCTION}

Nasopharyngeal cancer (NPC), commonly affecting Asian countries (incidence rate as high as 20-50 per 100.000 persons/year), is a very rare disease in Caucasian countries ( 0.5 new cases/year per 100.000 persons/year) $[1,2]$. Epstein-Barr Virus (EBV) is one of the most important causative factors of NPC. It has a heterogeneous diffusion, which might account, at least in part, for the different incidence between Southern China or Southeast Asia (endemic area) and Europe or USA (non-endemic area).

In the endemic area, the prognostic role of plasma EBV DNA viral load, with different cut-offs and detected before curative treatment for locally-advanced NPC patients, has been well described $[3,4,5,6]$.

To our knowledge, in the non-endemic area, only two limited case series (34 and 36 patients, respectively) investigating the role of EBV DNA have been reported $[7,8]$. These studies showed a direct relationship between pre-treatment EBV DNA viral load and baseline clinical tumor stage, and between EBV DNA increase and tumor recurrence during follow-up. Ferrari et al. [8] tried to demonstrate a prognostic significance of pre-treatment EBV DNA by reporting a significant correlation between higher baseline EBV DNA values and shorter DiseaseFree Survival (DFS) at univariate analysis (not confirmed after adjusting for age).

Therefore, the role of pre-treatment EBV DNA quantification for NPC patients in a non-endemic areas remains undefined. This study evaluates the prognostic role of baseline EBV DNA viral load for locally-advanced EBV-related NPC patients in a non-endemic area.

\section{RESULTS}

\section{Study population}

As shown in Table 1, 130 EBER-positive NPC patients were treated at our Institution with curative intent. The majority of patients were males $(66.9 \%)$, in good clinical conditions (ECOG PS 0-1: 95.4\%), young (median age: 48.5 , range: $18-81$ years), mainly staged as locally-advanced disease (86.2\%: III-IV stage) and treated with induction chemotherapy before concomitant CTRT (77.7\%: ICT with CTRT). One out of 5 patients was referred to our hospital after diagnostic neck surgery. The median b-EBV DNA viral load was 554 copies/mL with only 5 (3.8\%) positive UQ and 27 $(20.8 \%)$ negative patients. At a median follow-up of 43 months (range: 11-122) 28 patients recurred (21.5\%) and $18(13.9 \%)$ had died. The majority of recurrences (24/28; mean month: 37.9 , median month: 38 , range: 7-60 months) and all deaths (mean month: 40.9, median month: 43, range: 11-60 months) occurred within 5 years of follow-up.

\section{b-EBV DNA and its influencing factors}

Median b-EBV DNA viral load was significantly higher (Table 2) in patients with: ICT followed by CTRT $(P=0.006)$, higher tumor $\mathrm{T}$ and $\mathrm{N}$ stage (T4 and N3a-3b, $P=0.002$ and $P=0.048)$, locoregional and/or distant disease recurrence $(P=0.034)$.

\section{b-EBV DNA and outcome variables (DFS, OS)}

At univariate analysis, DFS was significantly longer in females $(P=0.035)$, patients who underwent neck surgery $(P=0.035)$, and those with lower T-stage (T1-2-3, $P=0.006)$ and negative $\mathrm{b}-\mathrm{EBV}$ DNA values $(P=0.002)$. OS was significantly longer in low T-staged (T1-2-3, $P=0.018)$ and negative b-EBV DNA NPC patients $(P=0.027)$. At multivariate analysis, only b-EBV DNA negativity (vs positivity) was confirmed as significantly independent influencing factor for both DFS and OS $(P=0.05$ and $P=0.06$, respectively). Kaplan-Meier survival curves (Figures 1,2) showed a significant relationship between b-EBV DNA status (negative vs positive) and outcome variables (DFS, $P=0.032$ and $\mathrm{OS}, P=0.029$ ).

\section{Identification of b-EBV DNA cut-off influencing outcome}

Considering b-EBV DNA as a categorical variable stratified into the 4 groups (Table 3), we disclosed a significant relationship between b-EBV DNA and DFS/ OS. The UQ, Q and Q+ b-EBV DNA groups showed similar results, thus suggesting that UQ behave as $\mathrm{Q}$ and $\mathrm{Q}+$. In order to verify this hypothesis, we re-run the test after grouping together UQ and Q. The results were the same (Table 3) and the relationship between b-EBV DNA and DFS and OS remained significant $(P<0.001)$, like when UQ and $\mathrm{Q}$ were considered separately. Using these three groups (UQ and $\mathrm{Q}, \mathrm{Q}+$, and Neg), we found that the UQ and Q group had the same behaviour as the $\mathrm{Q}^{+}$ group, whereas both differed from the Neg (Figure 3), thus suggesting that b-EBV DNA can be considered as a binary variable (positive or negative) regardless of the number of copies measured.

By ROC curve analysis (Area Under the Curve, $\mathrm{AUC}=0.640, P=0.009$ ) a $\mathrm{b}$-EBV DNA value of 3493 copies $/ \mathrm{mL}$ (Figure 4 ) was identified as cut-off of higher risk for loco-regional and/or distant recurrence with an accuracy of $72 \%$ (sensitivity: $53 \%$; specificity: $76 \%$ ).

\section{b-EBV DNA and outcome variables (DFS, OS) in a filtered-treatment study population}

The median b-EBV DNA value was 885 copies/ $\mathrm{mL}$ (range: $0-151075$ ) in a filtered-treatment study population including only patients treated with ICT followed by CTRT $(N=101)$. According to the results obtained in the overall population, b-EBV DNA was 
Table 1: Baseline characteristics of study population and descriptive statistics

Characteristics

$N(\%$ or range $)$

Gender

$\mathrm{M}$

$87(66.9)$

F

Median Age

$48.5(18-81)$

ECOG Performance Status

0-1

$124(95.4)$

2

Treatment

ICT followed by CTRT

$101(77.7)$

CTRT

$29(22.3)$

Neck surgery ${ }^{\mathrm{a}}$

YES

$26(20)$

NO

Stage (VII AJCC)

II

18 (13.8)

III

$40(30.8)$

IVa

$\mathrm{IVb}$

46 (35.4)

Median EBV DNA

$554(0-151075)$

EBV DNA $^{\mathrm{b}}$

UQ

Neg

27 (20.8)

Q

$50(38.5)$

$\mathrm{Q}^{+}$

48 (36.9)

Relapse

$28(21.5)$

Locoregional

$12(42.9)$

Distant

Death

Due to disease

Due to other causes

3 (16.7)

ECOG: Eastern Cooperative Oncology Group.

AJCC: American Joint Committee on Cancer.

${ }^{a}$ Lymph node neck dissection or excisional biopsy.

${ }^{\mathrm{b}}$ EBV DNA was stratified into 4 groups: Neg, Negative (EBV DNA $\left.=0\right)$; UQ, Positive but UnQuantifiable $(0<$ EBV

DNA $<10^{2}$ copies/mL); Q, Positive and quantifiable $\left(10^{2} \leq\right.$ EBV DNA $\leq 15$ x $10^{2}$ copies/mL $)$, Q+, Strongly positive and quantifiable (EBV DNA $>15 \times 10^{2}$ copies $\left./ \mathrm{mL}\right)$.

considered as a binary variable (positive/negative) and was significantly related with DFS $(P=0.004)$ and OS $(P=0.019)$ at univariate analysis.

Figures related to Kaplan-Meier survival curves (Supplementary Figure 1, Supplementary Figure 2) and the Tukey HSD post-hoc analysis results (Supplementary Figure 3) of the filtered-treatment study population are available as supplementary materials.

\section{DISCUSSION}

We showed the prognostic value of pre-treatment plasma EBV DNA viral load in a relatively high number of non-endemic EBV-related NPC patients. To date, all data regarding this issue derived from the main clinical trials conducted in the endemic area $[3,4,6]$. 
Table 2: Univariate analysis of b-EBV DNA and its influencing factors

\begin{tabular}{|c|c|c|}
\hline Characteristics & $\begin{array}{l}\text { EBV DNA } \\
\text { (median) }^{\mathrm{a}}\end{array}$ & $P$ value $^{b}$ \\
\hline \multicolumn{3}{|l|}{ Gender } \\
\hline M & 545 & 0.094 \\
\hline $\mathrm{F}$ & 577 & \\
\hline \multicolumn{3}{|l|}{ ECOG Performance Status } \\
\hline $0-1$ & 549.5 & 0.112 \\
\hline 2 & 6820 & \\
\hline \multicolumn{3}{|l|}{ Treatment } \\
\hline ICT followed by CTRT & 885 & 0.006 \\
\hline CTRT & 179 & \\
\hline \multicolumn{3}{|l|}{ Neck surgery ${ }^{\mathrm{c}}$} \\
\hline YES & 835 & 0.083 \\
\hline NO & 226.5 & \\
\hline \multicolumn{3}{|l|}{ T classification } \\
\hline $1-2-3$ & 387 & 0.002 \\
\hline 4 & 1745 & \\
\hline \multicolumn{3}{|l|}{ N classification } \\
\hline $0-1-2$ & 453 & 0.048 \\
\hline $3 a-3 b$ & 2153 & \\
\hline \multicolumn{3}{|l|}{ Recurrence } \\
\hline YES & 4609 & 0.034 \\
\hline $\mathrm{NO}$ & 480 & \\
\hline
\end{tabular}

a Excluded from this analysis the Unquantifiable EBV DNA group $(N=5)$.

b Continuous variable (age) was assessed using Spearman's correlation; categorical variables were assessed using nonparametric Mann-Whitney test.. Statistically significant $P$ values $(P<0.05)$ are highlighted.

${ }^{c}$ Lymph node neck dissection or excisional biopsy.

The median copy number of b-EBV DNA (554 copies $/ \mathrm{mL}$ ) and the prevalence of positivity (79.2\%) of plasma EBV DNA were quite lower than in the endemic area (median copy number: 681 for stage III, 1703 for stage IV; percentage of positivity: 94.9\%) [3].

The median b-EBV DNA value resulted significantly higher in patients with more advanced disease stage and/ or treated with ICT. The former observation reflects the correlation with the disease burden $[9,10,11,12,13]$; the latter may be explained by the fact that, during the entire time of our analysis, one of the criteria we adopted as Institutional policy for choosing ICT was b-EBV DNA higher than $15 \times 10^{2}$ copies/mL as well as T4 and/or N3 disease.
At multivariate analysis, b-EBV DNA value correlated with both recurrence of disease and survival outcomes (DFS, OS), overcoming the variable of ICT.

Differing from what observed in endemic NPC populations $[3,4,5,6]$, we were not able to identify any cut-off of b-EBV DNA as influencing DFS and OS. The few $(N=5)$ patients with unquantifiable positivity of b-EBV DNA, showed a similar behaviour as all other detectable b-EBV DNA groups thus supporting the informative baseline power of the test.

Our ROC curve analysis identified in 3493 copies/ $\mathrm{mL}$ a cut-off associated with an increased risk of locoregional and/or distant disease recurrence confirming in non-endemic area a trend of correlation between $\mathrm{b}-\mathrm{EBV}$ 


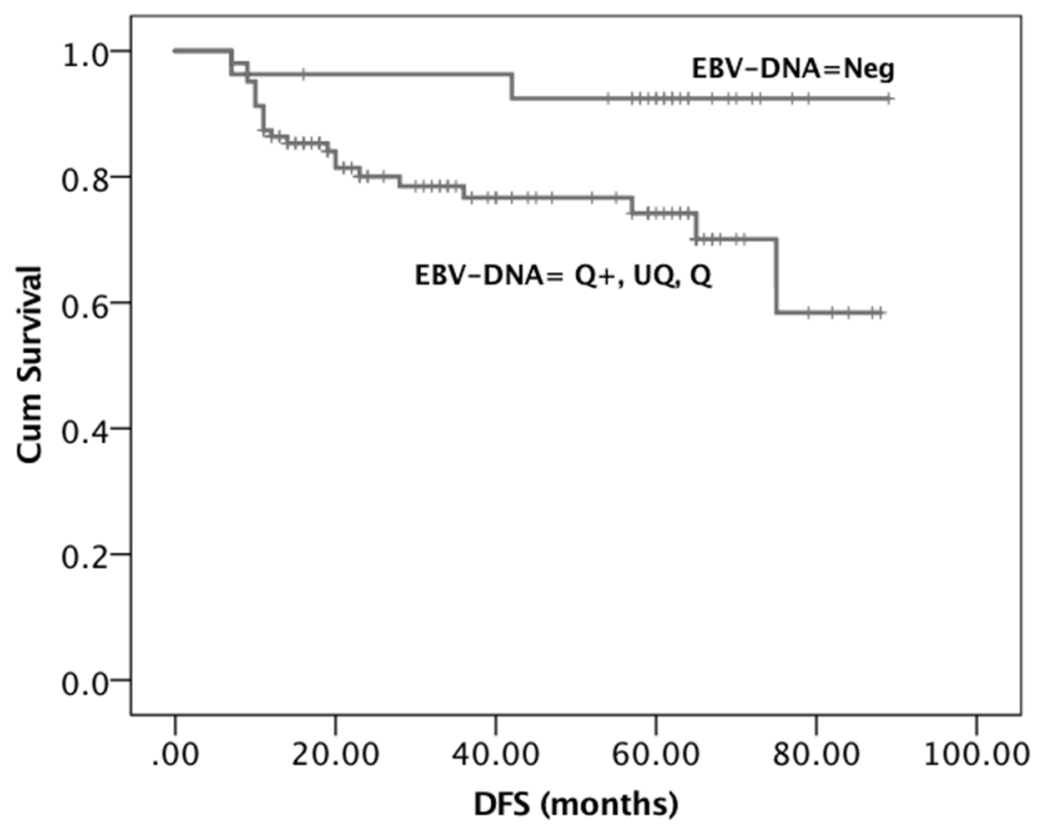

Figure 1: Kaplan-Meier survival curves showing the probability of DFS in locally advanced EBER positive NPC patients. DFS= Disease Free Survival. EBV DNA was stratified into 4 groups: Neg, Negative (EBV DNA = 0); UQ, Positive but UnQuantifiable $\left(0<\right.$ EBV DNA $<10^{2}$ copies $\left./ \mathrm{mL}\right)$; Q, Positive and quantifiable $\left(10^{2} \leq \mathrm{EBV}\right.$ DNA $\leq 15 \times 10^{2}$ copies $\left./ \mathrm{mL}\right)$; Q+, Strongly positive and quantifiable (EBV DNA $>15 \times 10^{2}$ copies $\left./ \mathrm{mL}\right)$.

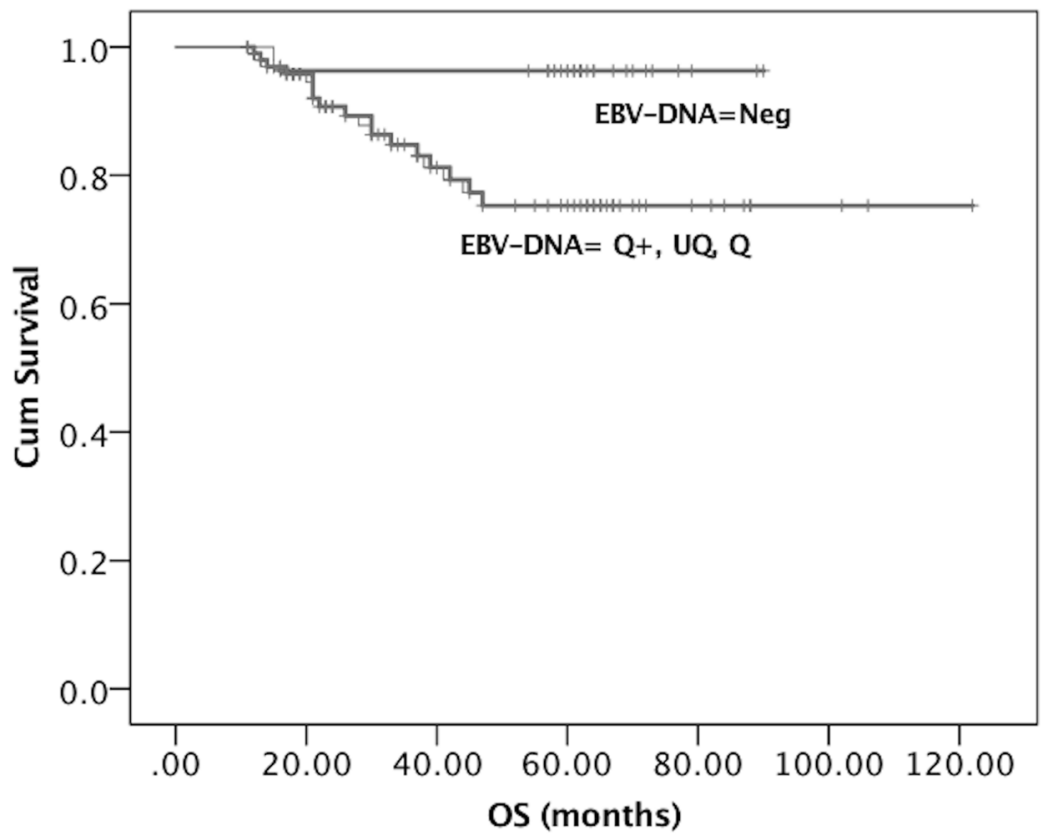

Figure 2: Kaplan-Meier survival curves showing the probability of $O S$ in locally advanced EBER positive NPC patients. OS= Overall Survival. EBV DNA was stratified into 4 groups: Neg, Negative $(\mathrm{EBV} D N A=0)$; UQ, Positive but UnQuantifiable $(0<\mathrm{EBV}$ DNA $<10^{2}$ copies $\left./ \mathrm{mL}\right) ; \mathrm{Q}$, Positive and quantifiable $\left(10^{2} \leq \mathrm{EBV}\right.$ DNA $\leq 15 \times 10^{2}$ copies $\left./ \mathrm{mL}\right) ; \mathrm{Q}+$, Strongly positive and quantifiable (EBV DNA $>15 \times 10^{2}$ copies $\left./ \mathrm{mL}\right)$. 
Table 3: Univariate analysis of b-EBV DNA and outcome variables (DFS, OS)

\begin{tabular}{|c|c|c|c|c|}
\hline EBV DNA ${ }^{a}$ & $\begin{array}{c}\text { DFS } \\
\text { (median) }\end{array}$ & $P$ value $^{b}$ & $\begin{array}{c}\text { OS } \\
\text { (median) }\end{array}$ & $P$ value $^{\mathrm{b}}$ \\
\hline \multicolumn{5}{|l|}{4 Groups } \\
\hline UQ & 13 & & 13 & \\
\hline Neg & 62 & 0.0001 & 62 & 0.0001 \\
\hline Q & 27 & & 31 & \\
\hline $\mathrm{Q}^{+}$ & 33.5 & & 37.5 & \\
\hline \multicolumn{5}{|l|}{3 Groups } \\
\hline UQ, Q & 23 & & 26 & \\
\hline $\mathrm{Q}^{+}$ & 33.5 & 0.0001 & 37.5 & 0.0002 \\
\hline Neg & 62 & & 62 & \\
\hline
\end{tabular}

a EBV DNA was stratified into 4 and 3 groups: Neg, Negative (EBV DNA = 0); UQ, Positive but UnQuantifiable $(0<$ EBV DNA $<10^{2}$ copies/mL); Q, Positive and quantifiable $\left(10^{2} \leq\right.$ EBV DNA $\leq 15 \times 10^{2}$ copies/mL $)$; Q+, Strongly positive and quantifiable (EBV DNA $>15 \times 10^{2}$ copies $\left./ \mathrm{mL}\right)$.

b The categorical variables were assessed using non-parametric Kruskal Wallis ANOVA. Statistically significant $P$ values $(P<0.05)$ are highlighted.

\begin{tabular}{|c|c|c|c|}
\hline EBV DNA Groups & Q+ & Neg & UQ, Q \\
\hline Q+ & & $\mathbf{0 . 0 0 0 0 5 3}$ & 0.935766 \\
\hline Neg & $\mathbf{0 . 0 0 0 0 5 3}$ & & $\mathbf{0 . 0 0 0 0 2 6}$ \\
\hline UQ, Q & 0.935766 & $\mathbf{0 . 0 0 0 0 2 6}$ & \\
\hline
\end{tabular}

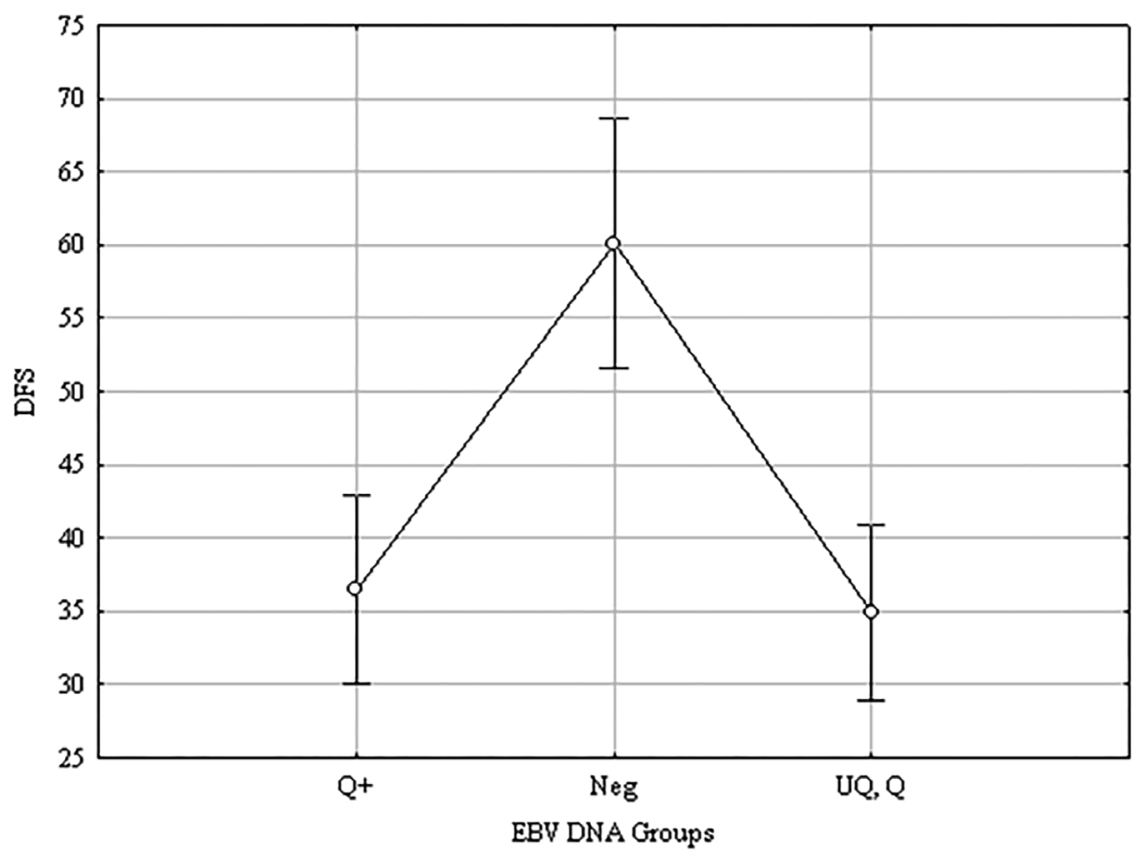

Figure 3: Results of Tukey HSD test. EBV DNA was stratified into 4 groups: Neg, Negative (EBV DNA = 0); UQ, Positive but UnQuantifiable $\left(0<\right.$ EBV DNA $<10^{2}$ copies $\left./ \mathrm{mL}\right)$; Q, Positive and quantifiable $\left(10^{2} \leq\right.$ EBV DNA $\leq 15 \times 10^{2}$ copies $\left./ \mathrm{mL}\right)$; Q,+ Strongly positive and quantifiable (EBV DNA $>15 \times 10^{2}$ copies $/ \mathrm{mL}$ ). The upper panel shows the results of the Tukey's HSD test: $P$ values corresponding to the difference between group pairs are displayed. Highlighted values are statistically significant $(P<0.05)$. The lower panel shows the median values of the three groups and their confidence intervals. 
DNA values progressively rising over the upper normal limits and recurrence.

This is in line with the results shown in an endemic population by Leung on 2003 [5] and Chen on 2016 [6]. They both found a cut-off of 4000 copies/mL for higher risk of development of distant metastases, which is one of the most important causes of treatment failure.

The main limitation of our analysis is the use of a laboratory method to measure circulating EBV DNA different from that used in the most robust published studies establishing the prognostic value of EBV DNA in NPC [3, 4], in which the primer/probe sets as target the BamHI-W region of the EBV genome [14]. BamHI-W fragment is repeated 8 to 11 times in the EBV genome, thus allowing more sensitive detection when compared with a single copy EBV genes $[15,16]$, such as Latent Membrane Protein (LMP2), Polymerase1 (POL1) or Epstein-Barr Virus Nuclear Antigen 1 (EBNA-1). This latter was used in this study and may explain why we identified a category (the UQ group) that has never been reported before. Possibly, a higher-sensible methodology could have moved this UQ category to the quantifiable group. Moreover, these discrepancies of the laboratory evaluations may be the reasons why we did not find a specific cut-off to significantly impact on outcome. Furthermore, the use of this different laboratory method could also explain why we detected a lower prevalence of positivity and median copy number of EBV DNA compared with endemic populations; to this respect, however, we cannot rule out that genetic factors (i.e., different genetic profile between Asian and non-Asian populations) have played a role.

On the other hand, the EBV DNA detection method targeting BamHI-W, which is a very variously repeated region among all EBV strains genomes, could be linked to a higher inter-subjects variability rate.

The commutability of all EBV DNA values across all different methods is a very debated issue [17, 18]. Le QT et al. [19] already stated that a prompt assay standardization is mandatory to reduce the intra and interlaboratory variability to ensure a better comparison of all worldwide collected plasma EBV DNA samples.

Another limitation of our analysis is the nonhomogeneous characteristic of the retrieved data. The main imbalance was due the high rate of patients having performed an ICT before locoregional treatment. However, we also demonstrated that this variable did not influence the prognostic value of b-EBV DNA.

Another weakness of our study is the lack of information about the post-treatment EBV DNA viral load detection which has already been recognized in endemic area as significantly related to worse prognosis when still detectable for 1 week $[3,4,20]$ to 1 month-time after chemo-radiotherapy completion [21]. Noteworthy, two ongoing randomized, phase III trials (NCT00370890 and NCT02363400) will evaluate NPC patients with residual EBV DNA to adjuvant chemotherapy or clinical observation only. The results of those trials will help to understand if post-treatment EBV DNA is the best factor for identifying patients more likely to benefit of the adjunctive therapies.

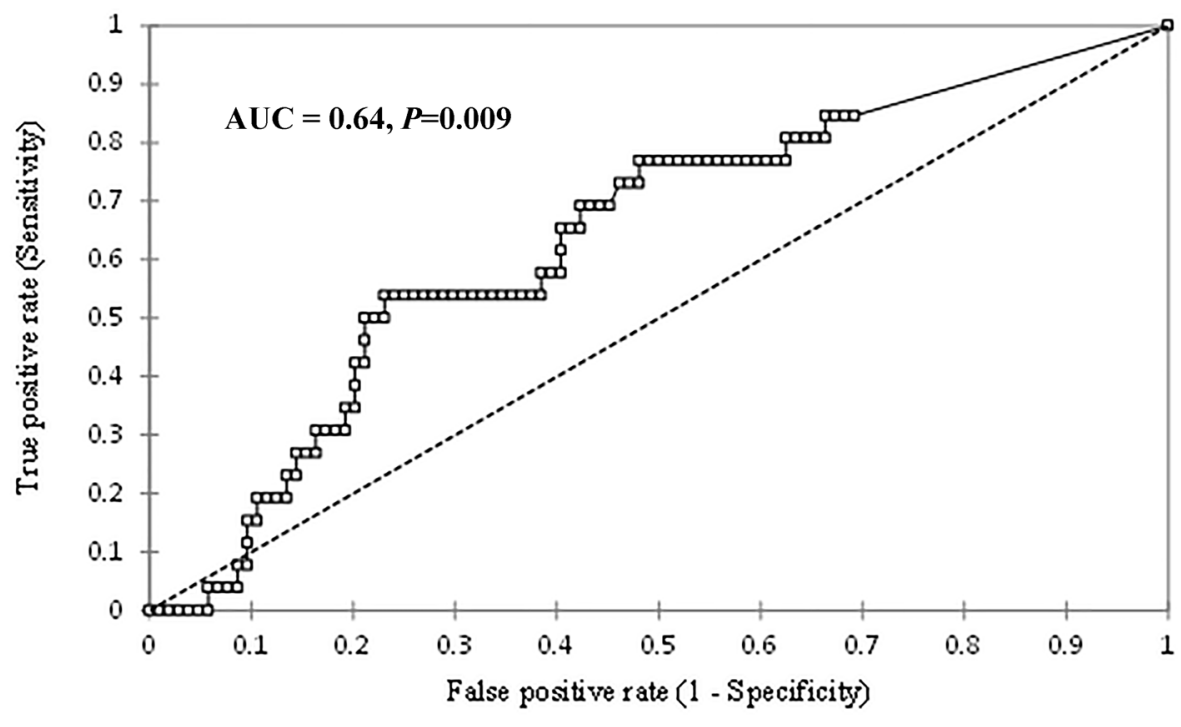

\begin{tabular}{|c|c|c|c|c|}
\hline EBV-DNA & Sensitivity & Specificity & Sensitivity + Specificity & Accuracy \\
\hline 3493 & $0.54(0.35-0.71)$ & $0.77(0.68-0.84)$ & 1.31 & 0.72 \\
\hline
\end{tabular}

Figure 4: Results of ROC curve analysis for the individuation of a possible value of b-EBV DNA as cut-off of higher risk of locoregional/distant recurrence. Top panel: ROC curve. The $\mathrm{x}$-axis is (1-Specificity); the y-axis is Sensitivity, Area Under the Curve $(\mathrm{AUC})=0.64, P=0.009$. Bottom panel: values of Specificity, Sensitivity, Accuracy, and Specificity+Sensitivity corresponding to the cut-off value of 3493 copies $/ \mathrm{mL}$. The lower and upper confidence intervals for Specificity and Sensitivity are reported in brackets. 
However, based on our findings that suggest a prognostic value of pre-treatment EBV DNA in patients belonging to non-endemic areas, we advocate for international cooperation to allow for standardized and inter-laboratory harmonized method of plasma EBV detection. A routinary and comparable quantification of EBV DNA may be of relevance for a timely monitoring of disease even in other settings, such as the follow-up phase and metastatic stage.

\section{MATERIALS AND METHODS}

We evaluated the pre-treatment baseline plasma EBV DNA (b-EBV) analysed in all EBV positive NPC patients treated with curative intent at the National Cancer Institute of Milan - a referral Center for the treatment of oncological disease in Northern Italy - from March 2005 to May 2014. EBV infection was determined by EBV encoded RNAs (EBER) in situ hybridization.

\section{EBV DNA detection}

EBV DNA levels were measured on plasma samples by real-time quantitative polymerase chain reaction (q-PCR) and were expressed as copies/mL. This measurement was performed at two Hospitals of Milan, Niguarda Ca' Granda Hospital and San Raffaele Hospital. Viral DNA extraction was performed by using the NucliSENS easyMAG kit (BioMérieux, Lyon, France) in Niguarda Hospital and Qiagen MDX kit in San Raffaele Hospital. In both Hospitals, EBV DNA quantification was performed by EBV Elite MGB kit according to the manifacturer's instructions. The system amplified the gene coding for Epstein-Barr Virus Nuclear Antigen 1 (EBNA1) protein.

The linear range of the assay was $10^{2}-10^{7}$ copies $/ \mathrm{mL}$ and the results of EBV DNA were expressed as follows: Not detected; Detected and Quantifiable $\left(\geq 10^{2}\right.$ copies $\left./ \mathrm{mL}\right)$; Detected but UnQuantifiable [UQ] $\left(<10^{2}\right.$ copies $\left./ \mathrm{mL}\right)$.

\section{Oncologic treatment}

Patients were treated with chemo-radiotherapy (CTRT) with or without induction chemotherapy (ICT) according to the standard practice of our Institute.

\section{Radiotherapy}

All patients were treated with intensity modulated radiotherapy (RT) techniques (IMRT, Intensity Modulated Radiation Therapy or VMAT, Volumetric Modulated Arc Therapy), with a curative intent. In all patients, total prescription dose was $70 \mathrm{~Gy}$, either by conventional fractionation (2 Gy per fraction, 5 fractions per week) or a moderately-hypofractionated regimen (2.12 Gy per fraction, 5 fractions per week), using a sequential or simultaneous integrated boost approach. All patients were staged with MRI of the head and neck district and whole body PET-CT scan before the initiation of oncological therapy; all images were fused with planning CT scans to better define target volumes. In patients receiving ICT, the extent of disease was re-evaluated with MRI after the last chemotherapy cycle. Planning procedures were usually performed shortly after the completion of ICT, and RT usually started within 3 to 4 weeks from the last cycle of induction chemotherapy.

\section{Chemotherapy}

In line with Institutional policies, ICT was prescribed in patients with: a) clinically-staged T4 and/or N3a-b NPC; b) Neck surgery (lymph node neck dissection or excisional biopsy) performed for diagnostic purposes; c) b-EBV DNA higher than $15 \times 10^{2}$ copies/mL according to the strongest dismal prognostic cut-off of b-EBV DNA recognized by Lin et al. [3]. In more details, Lin et al. showed that endemic NPC patients with baseline plasma EBV DNA concentrations $<1500$ copies/mL had better outcomes (in terms of OS and DFS) compared with those with pre-treatment EBV DNA values $\geq 1500$ copies $/ \mathrm{mL}$.

ICT was administered with TPF schedule for 3 cycles every 3 weeks (docetaxel $75 \mathrm{mg} / \mathrm{sm}$ on day 1 , cisplatin $75 \mathrm{mg} / \mathrm{sm}$ on day 1 , 5-fluororuracil $750 \mathrm{mg} / \mathrm{sm} /$ day on days 1 to 4 ) followed by antibiotic prophylaxis (ciprofloxacin at $500 \mathrm{mg}$ dose twice a day as standard) from $5^{\text {th }}$ to $15^{\text {th }}$ day after chemotherapy initiation. The use of growth-stem cell factors (G-CSF) as primary prevention for chemo-related neutropenia was limited to patients with intracranial disease or at high-risk of infection development. Concomitant chemotherapy regimen was weekly $(50 \mathrm{mg} / \mathrm{sm})$ or 3 -weekly $(100 \mathrm{mg} / \mathrm{sm})$ cisplatin (carboplatin AUC 5 was preferred if baseline creatinine clearance was lower than $60 \mathrm{ml} / \mathrm{min}$ ).

\section{Statistical analysis}

Descriptive statistics were calculated over main baseline patients [gender, age, Eastern Cooperative Oncology Group Performance Status (ECOG PS)], disease (T stage, N stage, VII AJCC Stage, locoregional and/or distant recurrence) and treatment characteristics (CTRT, CTRT with ICT, Neck Surgery).

We first investigated the relationship of b-EBV DNA viral load with all patients, disease, and treatmentrelated characteristics that could be considered influencing factors.

Univariate analysis was performed: non-parametric Mann-Whitney test (Gender, ECOG PS, CTRT vs CTRT with ICT, Neck Surgery) or non-parametric Kruskal Wallis ANOVA (T stage, N stage) was used for categorical variables $(P<0.05)$. Spearman's correlation 
(Age) was used for continuous variables $(P<0.05)$. Subjects with positive UQ EBV DNA value were excluded from this analysis; patients with $\mathrm{T}$ stage 1,2, and 3 were grouped together and compared with patients with $\mathrm{T}$ stage 4 , while patients with $\mathrm{N}$ stage 0,1 , and 2 were grouped together and compared with patients with $\mathrm{N}$ stage $3 \mathrm{a}$ and $3 \mathrm{~b}$.

Second, we investigated the relationship of outcome variables (DFS, OS) with the above-mentioned influencing factors and with b-EBV DNA. To this end, EBV DNA was stratified into 4 groups:

1. Negative (Neg): b-EBV DNA $=0$ copies $/ \mathrm{mL}$;

2. Positive but UnQuantifiable (UQ): $0<\mathrm{b}-\mathrm{EBV}$ DNA $<10^{2}$ copies $/ \mathrm{mL}$;

3. Positive and quantifiable (Q): $10^{2} \leq \mathrm{b}-\mathrm{EBV}$ DNA $\leq 15 \times 10^{2}$ copies $/ \mathrm{mL}$;

4. Strongly positive and quantifiable $\left(\mathrm{Q}^{+}\right)$: $\mathrm{b}-\mathrm{EBV}$ DNA $>15 \times 10^{2}$ copies $/ \mathrm{mL}$.

A cut-off of $15 \times 10^{2}$ copies $/ \mathrm{mL}$ was chosen in accordance with existing evidence [3], as previously mentioned. Tukey's Honest test was used for post-hoc analysis $(P<0.05)$.

Survival analysis (Kaplan-Meier) was conducted on OS and DFS with respect to all the variables that resulted significant at the univariate analysis.

In order to verify our results in a homogenously treated cohort of patients, we considered separately the subgroup of patients treated with ICT followed by CTRT or with CTRT alone. The same analysis described for the entire population was conducted in this subgroup. Last, a ROC analysis was performed on EBV DNA values in order to establish the threshold value that might better discriminate patients with recurrence from patients without recurrence.

\section{Author contributions} Bossi.

Conception and design: Salvatore Alfieri, Paolo

Provision of study materials or patients: Pasquale Quattrone, Annunziata Gloghini, Chiara Costanza Volpi, Diana Fanti, Sara Racca, Roee Dvir, Marco Guzzo, Roberto Bianchi, Ester Orlandi, Lisa Licitra.

Collection and assembly of data: Salvatore Alfieri, Carlo Resteghini, Laura Pala, Nicola Alessandro Iacovelli, Cristiana Bergamini, Roberta Granata.

Data analysis and interpretation: Salvatore Alfieri, Paolo Bossi, Sara Marceglia, Irene Lasorsa, Laura Locati, Lisa Licitra.

Manuscript writing: Salvatore Alfieri, Paolo Bossi, Sara Marceglia, Irene Lasorsa, Nicola Alessandro Iacovelli, Francesca Taverna, Arabella Mazzocchi, Diana Fanti.

Final approval of manuscript: All authors.

\section{ACKNOWLEDGMENTS}

We thank Dr Daniele Morelli and Dr Giovanni Pietro Gesu who participated with competence to this study. Editorial assistance for the preparation of this manuscript was provided by Luca Giacomelli, $\mathrm{PhD}$; and Lilia Biscaglia, PhD; this assistance was supported by internal funds.

\section{CONFLICTS OF INTEREST}

This study was conducted using internal funding. The authors declare no conflicts of interest.

\section{REFERENCES}

1. Jemal A, Bray F, Center MM, Ferlay J, Ward E, Forman D. Global cancer statistics. CA Cancer J Clin. 2011; 61:69-90.

2. Jeannel D, Bouvier G, Hubert A. Nasopharyngeal Carcinoma: an Epidemiological Approach to Carcinogenesis. Cancer Surveys. 1999; 33:125-155.

3. Lin JC, Wang WY, Chen KY, Wei YH, Liang WM, Jan JS, Jiang RS. Quantification of plasma Epstein-Barr virus DNA in patients with advanced nasopharyngeal carcinoma. New England Journal of Medicine. 2004; 350:2461-2470.

4. Wang WY, Twu CW, Chen HH, Jiang RS, Wu CT, Liang KL, Shih YT, Chen CC, Lin PJ, Liu YC, Lin JC. Long-term survival analysis of nasopharyngeal carcinoma by plasma Epstein-Barr virus DNA levels. Cancer. 2013; 119:963-970.

5. Leung SF, Chan AT, Zee B, Ma B, Chan LY, Johnson PJ, Lo YM. Pretherapy quantitative measurement of circulating Epstein-Barr virus DNA is predictive of posttherapy distant failure in patients with early-stage nasopharyngeal carcinoma of undifferentiated type. Cancer. 2003; 98:288-291.

6. Chen WH, Tang LQ, Guo SS, Chen QY, Zhang L, Liu LT, Qian CN, Guo X, Xie D, Zeng MS, Mai HQ. Prognostic Value of Plasma Epstein-Barr Virus DNA for Local and Regionally Advanced Nasopharyngeal Carcinoma Treated With Cisplatin-Based Concurrent Chemoradiotherapy in Intensity-Modulated Radiotherapy Era. Medicine. 2016; 95:e2642.

7. Bortolin MT, Pratesi C, Dolcetti R, Bidoli E, Vaccher E, Zanussi S, Tedeschi R, De Paoli P. Clinical value of EpsteinBarr virus DNA levels in peripheral blood samples of Italian patients with undifferentiated carcinoma of nasopharyngeal type. Cancer Letters. 2006; 233:247-254.

8. Ferrari D, Codecà C, Bertuzzi C, Broggio F, Crepaldi F, Luciani A, Floriani I, Ansarin M, Chiesa F, Alterio D, Foa P. Role of plasma EBV DNA levels in predicting recurrence of nasopharyngeal carcinoma in a Western population. BMC Cancer. 2012; 12:208. 
9. Chen M, Yin L, Wu J, Gu JJ, Jiang XS, Wang DJ, Zong D, Guo C, Zhu HF, Wu JF, He X, Guo WJ. Impact of plasma Epstein-Barr virus-DNA and tumor volume on prognosis of locally advanced nasopharyngeal carcinoma. Biomed Research International. 2015; 2015:617949.

10. Lu L, Li J, Zhao C, Xue W, Han F, Tao T, Chang H, Jia W, $\mathrm{Lu}$ T. Prognostic efficacy of combining tumor volume with Epstein-Barr virus DNA in patients treated with intensitymodulated radiotherapy for nasopharyngeal carcinoma. Oral Oncology. 2016; 60:18-24.

11. Leung SF, Zee B, Ma BB, Hui EP, Mo F, Lai M, Chan KC, Chan LY, Kwan WH, Lo YM, Chan AT. Plasma EpsteinBarr viral deoxyribonucleic acid quantitation complements tumor-node-metastasis staging prognostication in nasopharyngeal carcinoma. Journal of Clinical Oncology. 2006; 24:5414-5418.

12. Lo YM, Leung SF, Chan LY, Lo KW, Zhang J, Chan AT, Lee JC, Hjelm NM, Johnson PJ, Huang DP. Plasma cellfree Epstein-Barr virus DNA quantitation in patients with nasopharyngeal carcinoma. Correlation with clinical staging. Annals of the New York Academy of Sciences. 2000; 906:99-101.

13. Lu L, Li J, Zhao C, Xue W, Han F, Tao T, Chang H, Jia W, $\mathrm{Lu}$ T. Prognostic efficacy of combining tumor volume with Epstein-Barr virus DNA in patients treated with intensitymodulated radiotherapy for nasopharyngeal carcinoma. Oral Oncology. 2016; 60:18-24.

14. Lo YM, Chan LY, Lo KW, Leung SF, Zhang J, Chan AT, Lee JC, Hjelm NM, Johnson PJ, Huang DP. Quantitative analysis of cell-free Epstein-Barr virus DNA in plasma of patients with nasopharyngeal carcinoma. Cancer Research. 1999; 59:1188-1191.

15. Le QT, Jones CD, Yau TK, Shirazi HA, Wong PH, Thomas EN, Patterson BK, Lee AW, Zehnder JL. A comparison study of different PCR assays in measuring circulating plasma epstein-barr virus DNA levels in patients with nasopharyngeal carcinoma. Clinical Cancer Research. 2005; 11:5700-5707.

16. Stevens SJ, Verkuijlen SA, Hariwiyanto B, Harijadi, Fachiroh J, Paramita DK, Tan IB, Haryana SM, Middeldorp JM. Diagnostic value of measuring Epstein-Barr virus (EBV) DNA load and carcinoma-specific viral mRNA in relation to anti-EBV immunoglobulin A (IgA) and $\mathrm{IgG}$ antibody levels in blood of nasopharyngeal carcinoma patients from Indonesia. Journal of Clinical Microbiology. 2005; 43:3066-3073.

17. Abeynayake J, Johnson R, Libiran P, Sahoo MK, Cao H, Bowen R, Chan KC, Le QT, Pinsky BA. Commutability of the Epstein-Barr virus WHO international standard across two quantitative PCR methods. Journal of Clinical Microbiology. 2014; 52:3802-3804.

18. Tang L, Sun Y, Buelow D, Gu Z, Caliendo AM, Pounds S, Hayden RT. Quantitative Assessment of Commutability for Clinical Viral Load Testing Using a Digital PCR-Based Reference Standard. Jorunal of Clinical Microbiology. 2016; 54:1616-1623.

19. Le QT, Zhang Q, Cao H Cheng AJ, Pinsky BA, Hong RL, Chang JT, Wang CW, Tsao KC, Lo YM, Lee N, Ang $\mathrm{K}$, Chan AT, Chan KC. An international collaboration to harmonize the quantitative plasma Epstein-Barr virus DNA assay for future biomarker-guided trials in nasopharyngeal carcinoma. Clinical Cancer Research. 2013; 19:2208-2215.

20. Wang WY, Lin TY, Twu CW, Tsou HH, Lin PJ, Liu YC, Huang JW, Hsieh HY, Lin JC. Long-term clinical outcome in nasopharyngeal carcinoma patients with post-radiation persistently detectable plasma EBV DNA. Oncotarget. 2016; 7:42608-42616. doi: 10.18632/oncotarget.9323.

21. Chan AT, Lo YM, Zee B, Chan LY, Ma BB, Leung SF, Mo F, Lai M, Ho S, Huang DP, Johnson PJ. Plasma EpsteinBarr virus DNA and residual disease after radiotherapy for undifferentiated nasopharyngeal carcinoma. Journal of the National Cancer Institute. 2002; 94:1614-1619. 